\title{
Fibrin - Fibrinogen scaffold structural modification by phytochemicals and phytoproteases contained in an aqueous extract of Ageratum conyzoides Linn.
}

\author{
Amivi Edefia AKPALO*, Kwami Lumo AWAGA et \\ Amivi Kafui TETE-BENISSAN
}

Department of Biochemistry, University of Lome, BP: 1515 Lome, TOGO.

*Corresponding author; E-mail: edefia@gmail.com

\begin{tabular}{lll}
\hline Received: 16-10-2020 & Accepted: 09-02-2021 & Published: 28-02-2021 \\
\hline
\end{tabular}

\begin{abstract}
Based on mechanisms of fibrin clot polymerization and dissolution, it is possible to modulate fibrin formation and removal. Ageratum conyzoides Linn. (Asteraceae) is an annual herb with a long history of traditional medicine. There is high variability in the secondary metabolites of this plant which include flavonoids, and these molecules belong to a class of serine proteases inhibitors. Several plant enzymes belonging to the classes of serine proteases were observed to be active on the cascade of coagulation pathways. The aim of this study was to observe if even Ageratum conyzoides Linn. aqueous leaves extract contained proteases which could structurally modify the fibrin clot formation. To prepare plant extracts, dry leaves of the plant were extracted with distilled water. Fibrin gels were prepared by mixtures containing fibrinogen and thrombin with or without extract. Fibrin networks were disrupted by a denaturation buffer. Samples were deposited in $8 \%$ polyacrylamide gel and Coomassie blue was used to reveal migration. Our extract contained phytochemicals class flavonoids which are thrombin inhibitors. But our results support the evidence that the same extract contained plant serine proteases, specifically a fibrinogenase which hydrolyzed fibrinogen but not like thrombin.
\end{abstract}

(C) 2021 International Formulae Group. All rights reserved.

Keywords: Fibrin/Fibrinogen, structural modification, Ageratum conyzoides Linn., phytoproteases.

\section{INTRODUCTION}

The molecular mechanism of fibrin polymerization facilitates the formation of a wide range of fibrin network architectures. Those architectures influence clot stability, degradation properties and mechanics, which in turn modulate cellular behavior in the wound microenvironment (Sproul et al., 2018).
Based on mechanisms of fibrin clot polymerization and dissolution, it is possible to modulate fibrin formation and removal using pro-and anticoagulants, colloid fluids and thrombolytic therapy (Weisel and Litvinov, 2013). More, a multitude of parameters influence fibrin polymerization rates and resulting fiber structure including ionic strength, protein and zymogen concentrations, calcium concentration, and 
pH (Stabenfeldt et al., 2012). Ionic conditions, including $\mathrm{pH}$, ionic strength and composition; numerous endogenous and exogenous compounds, such as polyphosphate, oligo-and polysaccharides, peptides, lipids, medications, as well as albumin, fibronectin, lipoprotein(a), and other normal and pathological proteins present in plasma and injured tissues, influence clot structure (Weisel and Litvinov, 2013). Lower concentrations of thrombin can be used to alter network architecture at the expense of increased time to complete polymerization (Sproul et al., 2018). It is true thrombin plays a pivotal role in thrombogenesis (Liu et al., 2010). FXIII is transformed to activated FXIII by thrombin with the help of $\mathrm{Ca}^{2+}$ and catalyzes cross-linking of fibrin, converted from fibrinogen by activated thrombin (Shi and Wang, 2017).

Once the coagulation cascade is initiated, it operates via intrinsic and extrinsic pathway depending on the physiological conditions by intervention of serine proteases and clotting factors. So, proteases act sequentially all along the pathway to stop the bleeding process (Shivalingu et al., 2015).

$$
\text { Ageratum conyzoides Linn. }
$$

(Asteraceae) is an annual herb with a long history of traditional medicinal use in the tropical and sub-tropical region of the world. The mature plant is used for its haemostatic and anti-inflammatory properties for the treatment of wounds in bacterial infections (Singh et al., 2013).

There is high variability in the secondary metabolites of Ageratum conyzoides Linn. which include flavonoids, alkaloids, coumarins, essential oils and tannins. Among all, however, the plant contains more polyoxygenated flavonoids (Tailor et al., 2012), and in the last decade knowledges, flavonoids belong to a class of serine proteases inhibitors.

Proteases also known as proteolytic enzymes or peptidases, are a large group of enzymes which play a significant role in many biochemical mechanisms to maintain metabolic processes of all organisms (de Menezes et al., 2014). Proteases may be used for pharmacological purposes, such as blood coagulation and fibrinolysis. Several plant enzymes belonging to the classes of serine proteases were observed to be active on the cascade of coagulation pathways (de Menezes et al., 2014). Shivalingu et al. (2015), revealed that proteolytic activities of crude extracts fractions of Curcuma aromatica, Curcurma longa, Curcurma caesia and Curcuma amada was inhibited to a greater extent by PMSF (a specific serine protease inhibitor) compared to other specific protease inhibitors (Shivalingu et al., 2015). Clerofibrase was isolated from active anticoagulant fraction of Clerodendrum colebrookianum and demonstrated lower fibrinogenolytic and anticoagulant activity as compared to the anticoagulant active fraction of C. colebrookianum (Gogoi et al., 2019).

The aim of this study was to observe if even Ageratum conyzoides Linn. aqueous leaves extract obtained in our laboratories contained proteases which could structurally modify the fibrin clot formation.

\section{MATERIALS AND METHODS}

\section{Plant materials}

\section{Ageratum conyzoides Linn.}

The plant samples were collected in Niamtougou situated in the Kara region in Northern Togo. Vegetable sample was botanically authenticated as "E $9^{\circ} 41$ ' 22.6 " N $0^{\circ} 36$ '28.7" University of Lome from the National Forest Inventory of Togo database (IFN 2015). The fresh material was ovendried at a temperature not exceeding $37{ }^{\circ} \mathrm{C}$ for a week.

\section{Extraction}

To prepare plant extracts, dry leaves of Ageratum conyzoides Linn. finely cut $(10 \mathrm{~g}$ in weight) were extracted twice with distilled water $(150 \mathrm{ml}), 24$ hours at RT $\left(25^{\circ} \mathrm{C} \pm 2\right.$ $\left.{ }^{\circ} \mathrm{C}\right)$. Thereafter, $1 / 5$ dilution was performed by adding $60 \mathrm{~mL}$ of $95 \%$ ethanol. This extract solution was deposited overnight at RT $\left(25^{\circ} \mathrm{C} \pm 2{ }^{\circ} \mathrm{C}\right)$ and centrifuged at 4000 rpm for $10 \mathrm{~min}$. The supernatant was conserved at $+4{ }^{\circ} \mathrm{C}$ till protein assays occurred. 


\section{Proteins and chemicals}

Thrombin (T-4648) and fibrinogen (F3879) obtained from human plasma were purchased from Fisher Reagents (France).

All reactants were solubilized in 50 $\mathrm{mmol} / \mathrm{L}$ Tris- $\mathrm{HCl}$ buffer with $\mathrm{pH} 7.4$ and incubated at $37{ }^{\circ} \mathrm{C}$ for $15 \mathrm{~min}$ prior to mixing. Fibrin gels were prepared by incubation at $37{ }^{\circ} \mathrm{C}$ of a $1 \mathrm{~mL}$ mixture containing $5 \mathrm{mg}$ fibrinogen, 0.04 units of thrombin per $\mathrm{mg}$ of fibrinogen, $150 \mathrm{mmol} / \mathrm{L}$ $\mathrm{NaCl}, 20 \mathrm{mmol} / \mathrm{L} \mathrm{CaCl}_{2}$ and $50 \mathrm{mM}$ Tris$\mathrm{HCl}$ buffer with $\mathrm{pH}$ 7.4. This mixture was kept at $37{ }^{\circ} \mathrm{C}$ for $1 \mathrm{~h}$.

When extract was introduced in the gel, in situ, equivalent volume of Tris- $\mathrm{HCl}$ buffer, equivalent volume of thrombin or half volume of fibrinogen were added and completed if necessary, by Tris- $\mathrm{HCl}$ buffer. These mixtures were kept at $37^{\circ} \mathrm{C}$ for $1 \mathrm{~h}$.

To evaluate the dose-dependence degradation of fibrin gel, three samples of the later one were incubated respectively in the obtained plant extract (100\%), in 50\% diluted extract and in a solution containing only $20 \%$ of extract for $1 \mathrm{H}$, shaking at $500 \mathrm{rpm}$ at RT $\left(25^{\circ} \mathrm{C} \pm 2{ }^{\circ} \mathrm{C}\right)$.

The kinetics of fibrin gel degradation was determined by incubation of protein gels in the obtained plant extract for $0.5,1,1.5,2$ and $3 \mathrm{H}$.

\section{SDS-PAGE electrophoresis}

Fibrin networks (exclusive protein gel and in situ extract added gels) were disrupted by incubation for 24 hours at $37{ }^{\circ} \mathrm{C}$ in $4.5 \mathrm{~mL}$ of a mixture of $8 \mathrm{~mol} / \mathrm{L}$ urea, $2 \% \mathrm{w} / \mathrm{v}$ sodium dodecyl sulphate (SDS) and $2 \% \quad \mathrm{v} / \mathrm{v} \quad \beta-$ mercaptoethanol in $0.16 \mathrm{~mol} / \mathrm{L}$ Tris- $\mathrm{HCl}$ buffer with $\mathrm{pH}$ 6.8. This mixture was named denaturation buffer. Samples corresponding to 5 to $10 \mu \mathrm{g}$ proteins were deposited in $8 \%$ polyacrylamide gel. Coomassie blue was used to reveal migration.

When pre-formed gels were introduced post-synthesis in extract solutions, they were disrupted by adding $2 \mathrm{~mL}$ of denaturation buffer before submitted to electrophoresis analyses.

\section{RESULTS}

\section{Effect of plant extract on in situ formation} of fibrin gel

The first observation we did during the gel formation was a phenomenon either of precipitation or of syneresis when plant extract was present (Figure 1). We strongly hypothesized syneresis and not precipitation, as, when the gel was formed without stirring, any solution was expulsed before many hours.

To deeply understand the reaction exactly occurred during the gelation process, we proceed at different mixings modifying the initial protein gel composition. These modifications concerned the ratio $\mathrm{R}=\mathrm{V}_{\mathrm{e}}: \mathrm{V}_{\mathrm{f}}$ respectively extract volume and $1 \mathrm{~mL}$ total final volume. In the first mixing, there was any extract $(\mathrm{R}=0: 10)$, in the second one, extract volume equal initial buffer volume $(\mathrm{R}=3.8: 10$ ); in the third mixing, we introduced extract at a volume equal to initial thrombin one $(\mathrm{R}=0.1: 10)$, and in the fourth and last mixing, extract volume equal fibrinogen half one ( $\mathrm{R}=2.5: 10)$.

We then remarked that comparing gel with $\mathrm{R}=0.1: 10$ and gel with $\mathrm{R}=5: 10$, less expulsed solution was observed with the first one. That means this gel would retain almost all its liquid phase which was not the case of the gel with $\mathrm{R}=5: 10$.

For all in situ added extract, gelation time was 15 minutes instead of 2 minutes for exclusive fibrin protein gel. The gelation time was determined by the time stirring stopped. This second observation led us to study gelation process in presence of the plant extract. Electrophoresis analyses were performed after chemical degradation. Results are presented in Figure 2.

Well 1 containing hydrolyzed fibrin gel, $\mathrm{R}=0: 10$, exhibits characteristics bands of fibrin gel formation. Those bands are $A \alpha / \alpha$, $\mathrm{B} \beta / \beta, \gamma \gamma$ and $\alpha$-polymers. However, among 
these bands, the veritable fibrin formation characteristic band is the dimer $\gamma \gamma$. Well 2 containing hydrolyzed fibrin gel with plant extract at $\mathrm{R}=3.8: 10$ presents less intensity bands comparing to well 1 although these bands are the same. The characteristic $\gamma \gamma$ dimer is half less intensive as the $A \alpha / \alpha$ bands. Trace of $\gamma$ band which was inexistent in well 1 has appeared and very small molecular bands down of the electrophoresis gel has also appeared. Contrary, $\alpha$-polymers bands have almost completely disappeared. Wells 3 $(\mathrm{R}=0.1: 10)$ and $4(\mathrm{R}=5: 10)$ showed similar bands respectively as well $1(\mathrm{R}=0: 10)$ and well $2(\mathrm{R}=3.8: 10)$.

\section{Effect of plant extract loading on post- synthesis fibrin gel}

As in situ extract added to the fibrin gel seemed to negatively impact fibrin network organization, we tried to load the fibrin gel after its synthesis with the plant extract by immersing them (Figure 3 ).

The results obtained in this study show first of all absorption capacity of fibrin gel (Figures 3A and 3B). However, weight variations were not calculated. Then, in a second time, the results clearly indicate the presence of fibrinogenolytic enzymes in Ageratum conyzoides Linn. aqueous leaves extract as, gel immersed in more concentrated extract solution was more disrupted (almost at $90 \%$ ) than the gel immersed in only $20 \%$ concentrated extract solution (Figure 3C). The latter seemed to be disrupted only at $40 \%$. We, this time also, did not take weight variation. The fibrinogen cleavage pattern was analyzed by SDS-PAGE under reducing conditions, evaluating dose (Figure 4) and time dependances (Figure 5).

\section{Evaluation of dose-dependence hydrolysis of fibrin clot by plant extracts}

In order to verify the presence of fibrinolytic activity and dose-dependence of this activity, fibrin clots were incubated with plant extract at different concentrations $(100 \%, 50 \%$ and $20 \%)$ for $24 \mathrm{H}$ at room temperature $\left(25 \pm 2{ }^{\circ} \mathrm{C}\right)$. The reaction was stopped by addition of the denaturation buffer on the loaded fibrin gels.

The hydrolysis pattern was visualized by SDS-PAGE (Figure 4). We found that with decreasing extract concentration, bands related to the fibrin clot, namely $\gamma \gamma$ dimer bands regained progressively in intensity and $\gamma$ bands decreased progressively in intensity. More, high molecular weights $\alpha$-polymers bands and small molecular weights bands inversely varied in intensity. With concentrated extract solution (100\%), $\alpha$ polymers bands almost completely disappeared even though small molecular weights bands were present.

\section{Kinetics of fibrinogen hydrolysis by plant extract}

The kinetics of fibrin gel degradation by plant extract was determined by incubation of fibrin gels for $0.5,1,1.5,2$ and 3 hours. The incubation of plant extract with fibrin gels showed that substances present in the plant concentrated extract (100\%) hydrolyzed $A \alpha$ chain very efficiently within $0.5 \mathrm{H}$ of incubation while the hydrolysis of $\gamma$ chain is slower (about 1 hour). The high intensity of the hydrolyzed products, mean small molecular weights products, progressively increased until $1 \mathrm{~h} 30$ and then did not change over the incubation time. 


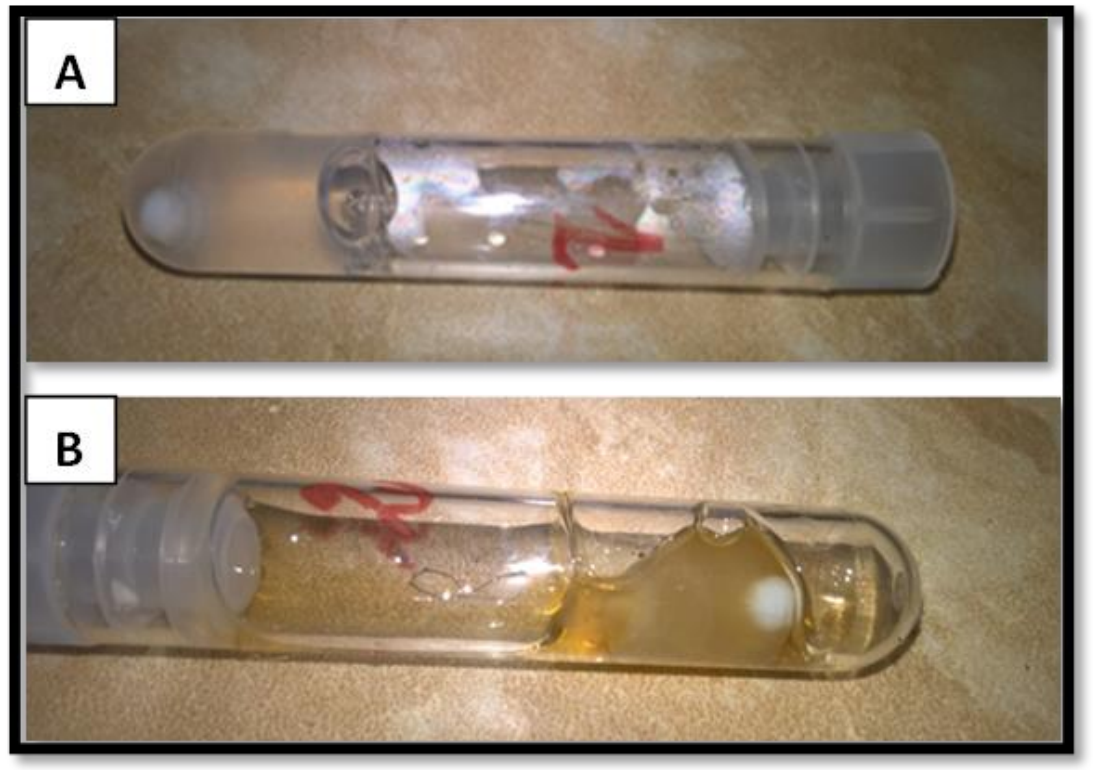

Figure 1: (A) Aspect of exclusive fibrin protein gel and (B) in situ extract added gels at a ration $\mathrm{R}=3.8: 10$.

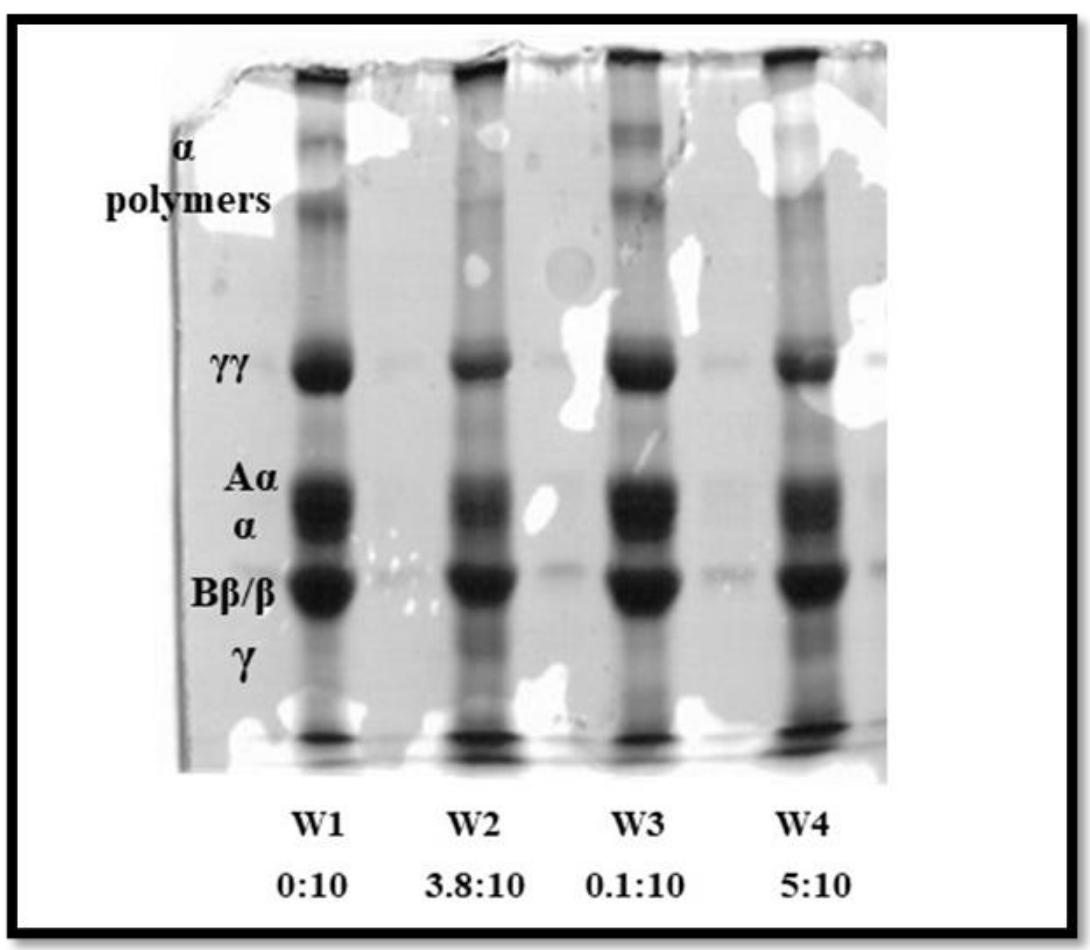

Figure 2: SDS-PAGE electrophoresis of exclusive fibrin protein gel (W1), in situ extract added gels at $\mathrm{R}=3.8: 10$ (W2), $\mathrm{R}=0.1: 10$ (W3), $\mathrm{R}=5: 10$ (W4). 

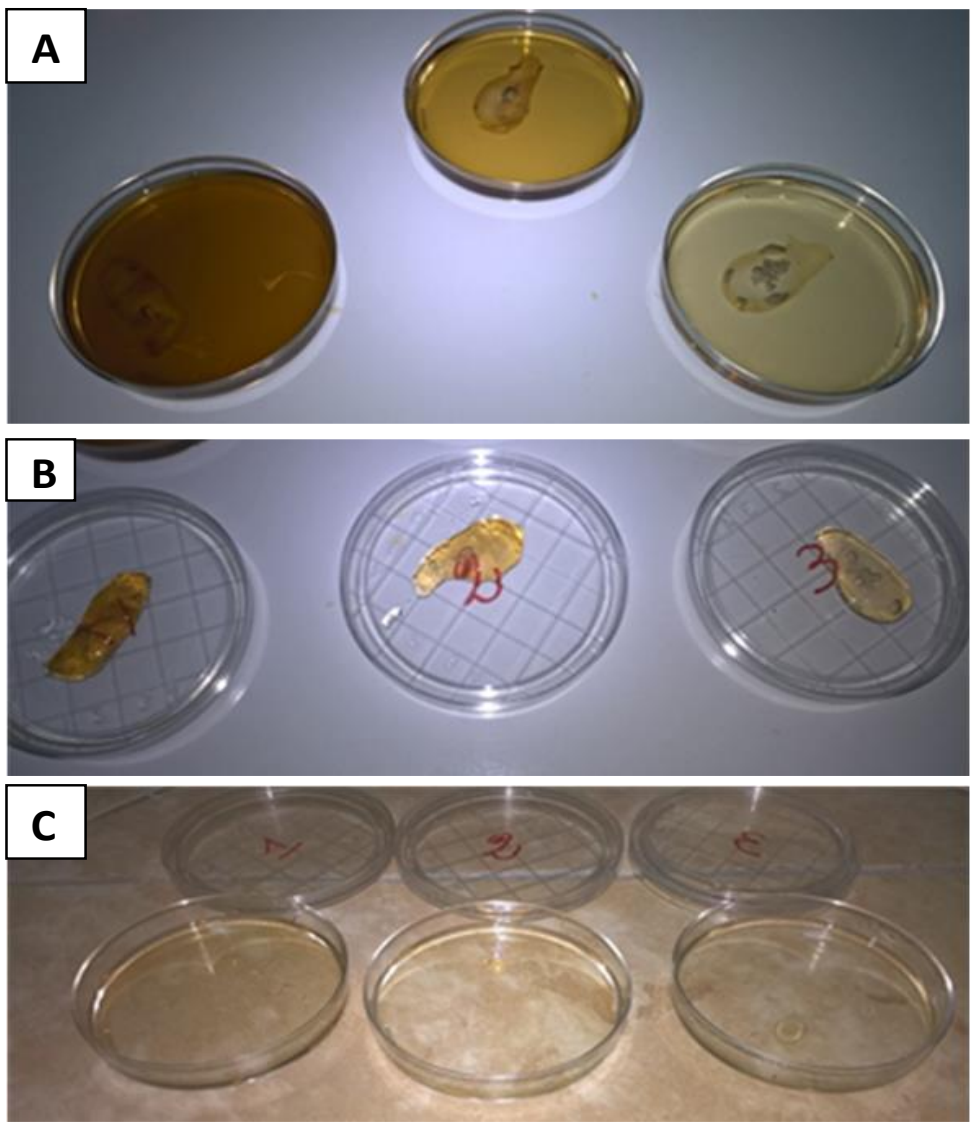

Figure 3: (A) Proteic gels immersed in 100\% (1), 50\% (2), 20\% (3) extract solutions; (B) Aspects of gels after 1 hour immersing in $100 \%$ (1), $50 \%$ (2), $20 \%$ (3) extract solutions; (C) Immersed proteic gels residuals after 24 hours of hydrolysis.

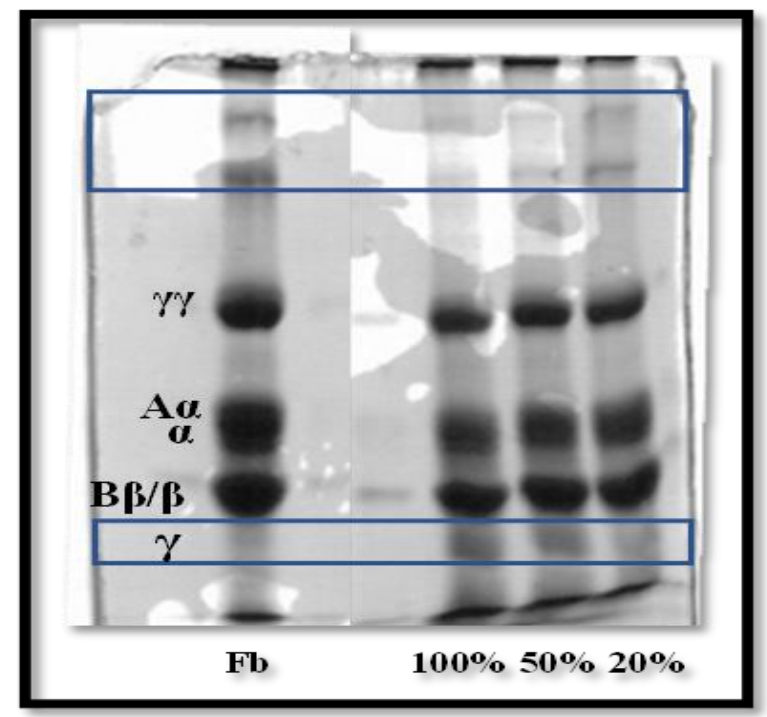

Figure 4: SDS-PAGE electrophoresis of immersed fibrin gels in concentrated extract (100\%), half diluted (50\%) and high diluted (20\%) plant extracts. 


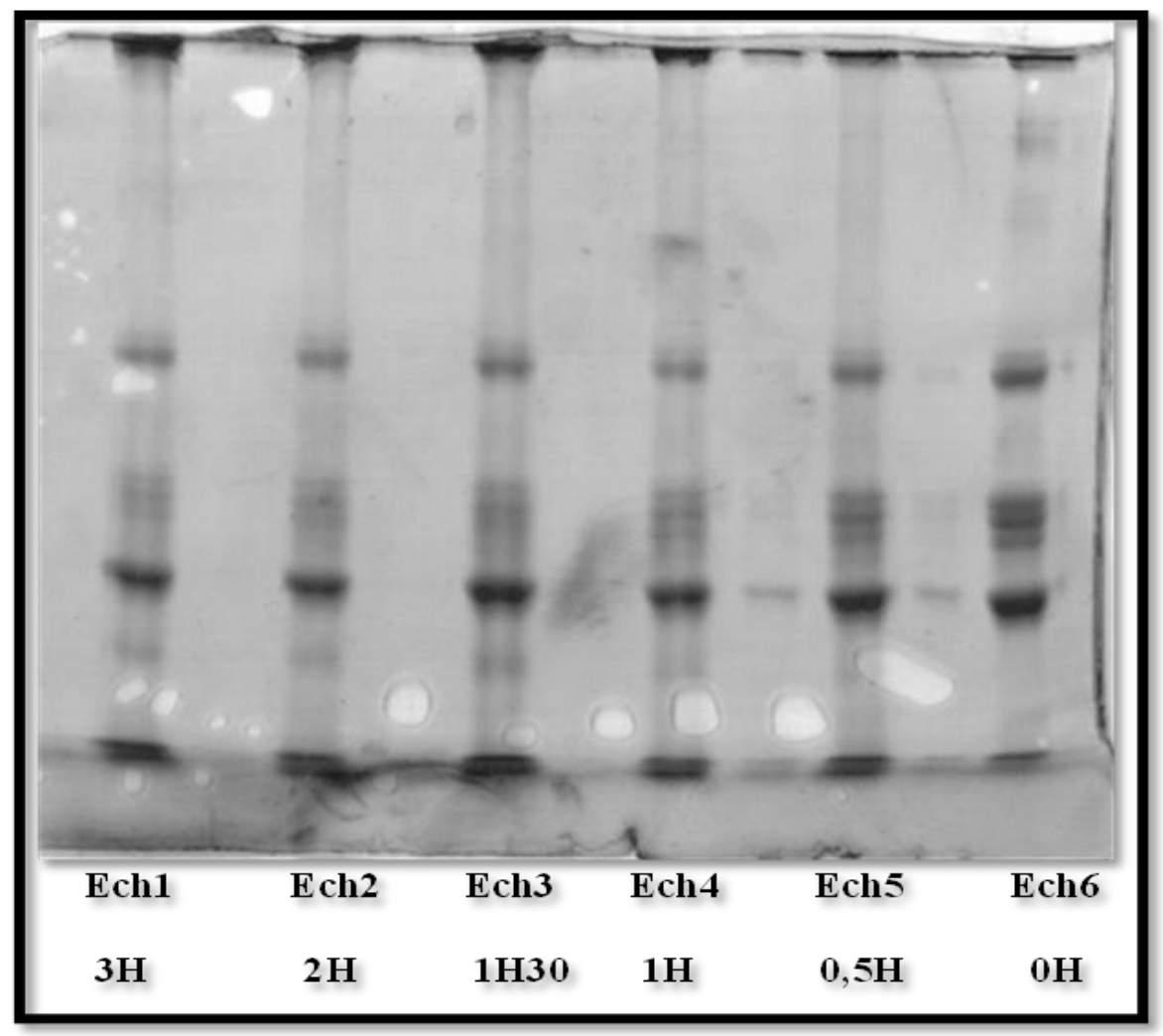

Figure 5: SDS-PAGE electrophoresis of immersed fibrin gels in concentrated extract (100\%) for 0 to 3 hours.

\section{DISCUSSION}

The presence in situ of the extract in the gel leads to the gel weakness and deeply to the weakness of some interactions. The fibrin scaffold is then less organized and probably contains less entrapped or attached protein molecules (small molecular weights products are present in electrophoresis). The extract certainly prevented normal hydrolysis of fibrinogen to fibrin as it contains thrombin inhibitors (Akpalo et al., 2020a). As consequences, normal fibrin molecules interactions to form the scaffold were disturbed. A similar phenomenon was previously described. Adding a highly active microbial transglutaminase which can crosslink both fibrin and fibrinogen before adding thrombin did not allow the formation of a regular gel. The hydrolysis of fibrinogen by thrombin and the obtention of a well- organized network were prevented or delayed (Akpalo and Larreta-Garde, 2010).

When syneresis occurs, means spontaneous release of water from the gel structure due to the contraction of the last one, many hypotheses are advanced. The gelation temperature and gel elasticity play important roles in the syneresis behavior; the higher the gel strength is, the smaller the syneresis effect becomes (Ako, 2017). Syneresis is the contraction of a colloidal gel. Contraction of the fibrin clot impacts microenvironments of water around the various components within the blood sample, including soluble proteins, erythrocytes, and the fibrin network itself, leading to the formation of multiple water compartments (Skewis et al., 2014). In this study, fibrin gel is a veritable colloidal gel as it is an in vitro acellular one and previous studies have determined rheological properties (Akpalo 
and Larreta-Garde, 2010) of different kinds of fibrin gels. Fibrin soft gels are formed subsequent to the thrombin hydrolysis of the fibrinogen molecules and fibrin polymerization. In our mind, phenomenon occurring, is certainly syneresis due first, to thrombin inhibition by plant extract substances previously demonstrated (Akpalo et al., 2020a); secondly, osmotic pressure leading to exudate of incorporated extract mixing with gel liquid phase and its molecules (ions, not attached fibrinogen and fibrin molecules,...). The stirring has pronounced this phenomenon. There are less fibrinogen attached molecules in the scaffold when plant extract was added.

When electrophoresis analyses were performed to deeply understand and confirmed this phenomenon, we remark a real decrease in the intensity of fibrin formation characteristic bands when plant extract was present at $\mathrm{R}=3.8: 10$ and $\mathrm{R}=2.5: 10$. Akpalo et al. (2010) had yet demonstrated that with a high transglutaminase concentration, inducing non ordered cross-linking, up to $63 \%$ of the proteins were not included in the network but were present in the liquid phase contained inside the gel (Akpalo and LarretaGarde, 2010). However, only about $20 \%$ of the proteins were not included in the gel network, in the absence of transglutaminase. Then decrease intensity of characteristic bands, namely of $\gamma \gamma$ dimer band traduces less protein in the gel network due certainly to thrombin enzymatic hydrolysis inhibition by the plant extract. More, the presence of $\gamma$ monomer band indicates a defect in fibrin network formation and presence of not incorporated protein molecules. The last but not least remark, was the presence of small molecular protein bands down the electrophoresis gel; we then strongly suppose the plant extract induced another fibrinogen/fibrin molecules hydrolysis. Global decrease intensity may correspond to more hydrolysis. Research works conducted in our laboratory on Ageratum conyzoides Linn. plant extract, demonstrated this extract contains flavonoids which are serine proteases inhibitors (Akpalo et al., 2020a).
Thrombin was then probably inhibited as $\alpha$ polymers, $\alpha$ and $\beta$ bands disappeared. Any inhibitory test was down but according to de Menezes et al. (2014) and Shivalingu et al. (2015) who obtained similar results, these results suggest that our extract contained besides a serine protease fibrinogenase.

The fibrinogen and fibrin bands present in electrophoresis gels were obtained by submitted the different types of protein gels to a denaturation solution containing 8 $\mathrm{mol} / \mathrm{L}$ urea. The ability of urea to dissolve certain fibrin clots suggests that hydrogen bonds are involved but the bond energies of hydrogen bridges are so low (about 1/10 as strong as most covalent bonds) that probably hundreds would be necessary for each molecule. This would imply an improbably close alignment of each fibrinogen molecule to the next. The electrostatic forces then align two molecules side by side and overlapping; the peptide GHRP, which reproduces the structure of knob 'B', has a much lower equilibrium binding affinity for fibrinogen $(\mathrm{Kd}=140 \mu \mathrm{M})$ compared to the peptide GPRP $(\mathrm{Kd}=25 \mu \mathrm{M})$ that mimics the structure of knob 'A (Weisel et al., 2017)

The urea solubility of the clots is probably affected by the lowering of the calcium ions concentration as urea can lead to irreversible changes of protein charge, Fibrinogen has both strong and weak binding sites for calcium ions, which are important for its functions, including fibrin polymerization, and lytic stability (Weisel et al., 2017). The rate and degree of lateral aggregation that occurs within a fibrin network can also be influenced by the presence of calcium; fibrinogen molecules contain two binding sites for $\mathrm{Ca}^{2+}$ ions $-\mathrm{a}$ high affinity $\gamma 1$ site and a low affinity $\gamma 2$ site - which help confer stability to the fibrinogen molecule and allow the polymerization process to occur (Sproul et al., 2018). Our denaturation solution contained $8 \mathrm{M}$ urea.

Then, when protein gels with in situ extract added or protein gels immersed in variable extract solutions are degraded proportionally to extract contains or concentrations, calcium ions could also be 
used by some molecules present in the plant extract, stability of hydrogen bonds are concerned. So, extract solutions destabilized seriously hydrogen bonds in fibrin network. All electrophoresis analyses demonstrated less well-formed fibrin network by $\gamma \gamma$ dimer intensity diminution as $\alpha$-polymers also.

Thrombin, a serine protease acts on fibrinogen and converts it into insoluble fibrin clot. The fibrin monomers undergo polymerization, retract with platelet contractile protein and stop bleeding by the formation of strong hemostatic plug. Furtherly, the serine protease plasmin dissolves thrombi and hemostatic plugs through the action on fibrin, facilitating wound healing and promote flow of blood (Shivalingu et al., 2016). The fibrin network must be stable enough to establish hemostasis and promote initial cell infiltration; however, improper degradation kinetics can impede wound healing from progressing into the subsequent stages of remodeling. Plasmin along with matrix metalloproteases (MMPs), degrade fibrin into a variety of degradation products responsible for the chemotaxis, recruitment, and activation of macrophages (Sproul et al., 2018).

In the fibrinogenolytic activity assay, it was found that fibrinogen $\gamma$ chain was cleaved at high plant extract concentration or an extended incubation time (de Menezes et al., 2014). We have similar results. It has been reported that, in general, proteases which hydrolyze fibrinogen $\gamma$ subunit are also able to hydrolyze fibrin clot (de Menezes et al., 2014).

The crude extracts fractions of Curcurma aromatica, Curcurma longa and Curcurma caesia, showed complete hydrolysis of $\mathrm{A} \alpha(63.5 \mathrm{kDa}), \mathrm{B} \beta(56.0 \mathrm{kDa})$ and $\gamma(47.0 \mathrm{kDa})$ subunits of fibrinogen, whereas Curcuma amada and Curcuma zedoria showed partial hydrolysis (Shivalingu et al., 2015). Although the crude extracts fractions hydrolyzed $\alpha, \beta$ and $\gamma$ fibrinogen, unlike thrombin, it did not induce the clot formation with purified fibrinogen. This data indicated that the crude extracts fractions lack thrombin like activity and its site of action on fibrinogen is totally different from that of thrombin (Shivalingu et al., 2015).

The purified and characterized protease from Curcuma aromatica is named CAP-II. CAP-II hydrolyzed all the three subunits of human fibrinogen in a dose dependent manner (Shivalingu et al., 2016) and the hydrolysis of different subunits is in the order of $\mathrm{A} \alpha>\mathrm{B} \beta>\gamma$. The CAP-II exhibited time dependent $\left(\begin{array}{lll}0 & -120 & \mathrm{~min}\end{array}\right)$ hydrolysis of fibrinogen. With the increase in incubation time from 5 to $60 \mathrm{~min}$ showed the hydrolysis of $A \alpha$ and $B \beta$ subunits of fibrinogen, whereas $\gamma$ subunit remained resistant to hydrolysis even at $120 \mathrm{~min}$ incubation time (Shivalingu et al., 2016). Unlike thrombin, CAP-II did not induce the clot formation with purified fibrinogen. This data indicated that CAP-II lack thrombin like activity and its site of action on fibrinogen is totally different from that of thrombin (Shivalingu et al., 2016).

The CAP-II showed potent fibrinogenolytic activity, which indicates initiations of next phases of wound healing by hydrolysis of hemostatic plug of wound. Fibrinogenolytic enzymes act by cleaving the fibrinogen molecule at sites distinct from those cleaved by thrombin, turning the fibrinogen incoagulable (de Menezes et al., 2014). The $\alpha$-fibrinogenases from different medicinal plants, such as Costaria costata and Codium fragile were reported to hydrolyze the A $\alpha$-subunit of fibrinogen. Clerofibrase is considered an $\alpha \beta$ fibrinogenase, because it can degrade both $\alpha$ and $\beta$-chains of fibrinogen, demonstrating a fibrinogen degradation pattern that differs from other plant proteases (Gogoi et al., 2019).

Fibrinogen disintegration gives smaller fragments known as fibrin, which helps in developing blood vessels from the area exhaust with oxygen, nutrients and various immune cells that are responsible for tissue repair (Shivalingu et al., 2016). 


\section{Conclusion}

Fibrin plug formation and fibrinolysis are the two main proteolytic events in hemostasis associated with wound healing. Fibroblasts migrating into the fibrin network deposit collagen and secrete plasminogen activators which contribute to fibrin lysis, thus favoring neovascularization. Our extract contains phytochemicals class flavonoid which are thrombin inhibitors. But our results support the evidence that the same extract contains plant serine proteases, specifically a fibrinogenase which hydrolyzed fibrinogen but not like thrombin. Further studies would demonstrate our fibrin lysis products favorize neovascularization by developing blood vessels from the area for tissue repair.

\section{COMPETING INTERESTS}

The authors have not declared any competing interests.

\section{AUTHORS' CONTRIBUTIONS}

AEA conceived the research idea, made the extractions and electrophoresis, analyzed the data and wrote the draft. KLA provided technical assistance and made valuable comments on the manuscript. AKTB gave valuable scientific critical advises.

\section{ACKNOWLEDGEMENTS}

We would also like to extend our gratitude to Soroptimist International of Europe (SIE) for funding this project and to the anonymous reviewers for their valuable comments and suggestions made to help improve the manuscript.

\section{REFERENCES}

Ako K. 2017. Influence of osmotic and weight pressure on water release from polysaccharide ionic gels. Carbohydrate Polymers, 169: 376-384. DOI: https://doi.org/10.1016/j.carbpol.2017.0 4.062

Akpalo E, Larreta-Garde V. 2010. Increase of fibrin gel elasticity by enzymes: A kinetic approach. Acta Biomaterialia, 6: 396-402.

DOI: https://doi.org/10.1016/j.actbio.2009.08. 001

Akpalo AE, Saloufou IK, Eloh K, Kpegba K. 2020a. Wound healing biomolecules present in four proposed soft aqueous extractions of Ageratum conyzoides Linn. Int. J. Bio. Chem. Sci., 14(2): 638-651.

DOI: https://doi.org/10.4314/ijbcs.v14i2.26

Akpalo AE, Douti FV, Layibo Y, Feteke L, Karou S. 2020b. Plasma fibrin sealant exclusively based on exogenous calcium and physiological thrombin: fitting and understanding of an old approach. Annals of Biomedical Sciences, 19: 1.

de Menezes Y, Félix-Silva J, da Silva-Júnior A, Rebecchi I, de Oliveira A, Uchoa A, Fernandes-Pedrosa M. 2014. ProteinRich Fraction of Cnidoscolus urens (L.) Arthur Leaves: Enzymatic Characterization and Procoagulant and Fibrinogenolytic Activities. Molecules, 19: 3552-3569. DOI: https://doi.org/10.3390/molecules19033 552

Gogoi D, Ramani S, Bhartari S, Chattopadhyay P, Mukherjee AK. 2019. Characterization of active anticoagulant fraction and a fibrin(ogen)olytic serine protease from leaves of Clerodendrum colebrookianum, a traditional ethnomedicinal plant used to reduce hypertension. Journal of Ethnopharmacology, 243: 112099. DOI: https://doi.org/10.1016/j.jep.2019.11209 9

MERF/GIZ, 2016. Inventaire Forestier National. ProREDD, Lomé.

Liu L, Ma H, Yang N, Tang Y, Guo J, Tao W, Duan J. 2010. A Series of Natural Flavonoids as Thrombin Inhibitors: Structure-activity relationships. Thrombosis Research, 126: e365-e378. DOI:

https://doi.org/10.1016/j.thromres.2010. 08.006

Skewis LR, Lebedeva T, Papkov V, Thayer EC, Massefski W, Cuker A, Nagaswami C, Litvinov RI, Kowalska MA, Rauova L, Poncz M, Weisel JW, Lowery TJ, 
Cines DB. 2014. T2 Magnetic Resonance: A Diagnostic Platform for Studying Integrated Hemostasisin Whole Blood-Proof of Concept. Clinical Chemistry, 60: 91174-91182

Shi DY, Wang SJ. 2017. Advances of Coagulation Factor XIII. Chin. Med. J., 20 : 219-223. DOI: 10.4103/03666999.198007

Shivalingu BR, Vivek HK, Nafeesa Z, Priya BS, Swamy SN. 2015. Comparative analysis of procoagulant and fibrinogenolytic activity of crude protease fractions of turmeric species. Journal of Ethnopharmacology, 172: 261-264. DOI: https://doi.org/10.1016/j.jep.2015.06.01 8

Shivalingu BR, Vivek HK, Priya BS, Soujanya KN, Swamy SN. 2016. Purification and characterization of novel fibrin(ogen)olytic protease from Curcuma aromatica Salisb.: Role in hemostasis. Phytomedicine, 23: 16911698.

DOI: https://doi.org/10.1016/j.phymed.2016.0 9.007

Singh SB, Devi WR, Devi WI, Swapana N, Singh CB. 2013. Ethnobotany, phytochemistry and pharmacology of Ageratum conyzoides Linn (Asteraceae). Journal of Medicinal Plant Research, 7: 8.
Sproul E, Nandi S, Brown A. 2018. Fibrin biomaterials for tissue regeneration and repair, in: Peptides and Proteins as Biomaterials for Tissue Regeneration and Repair. Elsevier, 151: 173. DOI: https://doi.org/10.1016/B978-0-08100803-4.00006-1

Stabenfeldt SE, Gourley M, Krishnan L, Hoying JB, Barker TH. 2012. Engineering fibrin polymers through engagement of alternative polymerization mechanisms. Biomaterials, 33: 535-544. DOI: https://doi.org/10.1016/j.biomaterials.20 11.09.079

Tailor CS, Goyal A. 2012. A Comprehensive Review on Ageratum conyzoides Linn. (Goat weed). International Journal of Pharmaceutical and Phytopharmacological Research, 1: 6.

Weisel JW, Litvinov RI. 2013. Mechanisms of fibrin polymerization and clinical implications. Blood, 121: 1712-1719. DOI: https://doi.org/10.1182/blood2012-09-306639

Weisel JW, Litvinov RI. 2017. Fibrin Formation, Structure and Properties. Subcell Biochem., 82: 405-456. DOI: 10.1007/978-3-319-49674-0_13. 